\title{
Light Spectrum Impacts on Growth, Molting, and Oxidative Stress Response of the Mud Crab Scylla paramamosain
}

\author{
Shujian Chen 1,2,3, Ce Shi 1,2,3*, Herve Migaud ${ }^{2,3,4}$, Changbin Song ${ }^{5}$, Changkao $\mathrm{Mu}^{2,3}$, \\ Yangfang $\mathrm{Ye}^{2,3}$, Chunlin Wang ${ }^{2,3}$ and Zhiming Ren ${ }^{2,3}$
}

\begin{abstract}
'Marine Economic Research Center, Donghai Academy, Ningbo University, Ningbo, China, ${ }^{2}$ Key Laboratory of Applied Marine Biotechnology, Ningbo University, Chinese Ministry of Education, Ningbo, China, ${ }^{3}$ Collaborative Innovation Center for Zhejiang Marine High-Efficiency and Healthy Aquaculture, Ningbo, China, ${ }^{4}$ Institute of Aquaculture, University of Stirling, Stirling, United Kingdom, ${ }^{5}$ Institute of Semiconductors, Chinese Academy of Sciences, Beijing, China
\end{abstract}

OPEN ACCESS

Edited by:

Valerio Matozzo,

University of Padua, Italy

Reviewed by:

Hanafiah Fazhan,

Shantou University, China

Changhong Cheng,

South China Sea Fisheries Research

Institute (CAFS), China

*Correspondence:

Ce Shi

shice3210@126.com

Specialty section: This article was submitted to

Aquatic Physiology,

a section of the journal

Frontiers in Marine Science

Received: 21 December 2021 Accepted: 31 January 2022

Published: 04 March 2022

Citation:

Chen S, Shi C, Migaud H, Song $C, M u C$, Ye Y, Wang $C$ and Ren Z (2022) Light Spectrum Impacts on Growth, Molting, and Oxidative Stress Response of the Mud Crab

Scylla paramamosain.

Front. Mar. Sci. 9:840353. doi: 10.3389/fmars.2022.840353
An 8 weeks trial was performed to test the effects of light spectra [full-spectrum, violet (405 nm), blue (470 nm), cyan (500 nm), green (525 nm), yellow (570 nm), and red $(625 \mathrm{~nm})]$ on growth performance, molting, antioxidant capacity, stress response and expression of molting, and apoptosis-related genes in Scylla paramamosain. Results showed that spectrum had a significant effect on S. paramamosain physiology. Compared to blue light, crabs exposed to violet light had a significantly lower survival rate $(79.5 \pm 3.6 \%$ vs. $94.9 \pm 3.6 \%)$, weight gain $(49.2 \pm 5.4$ vs. $67.6 \pm 6.7)$, molt frequency ( $4.2 \pm 0.2$ vs. $4.5 \pm 0.1$ ), and extended intermolt intervals between instar 1 and 2 stages $(\mathrm{C} 1-\mathrm{C} 2)(6.3 \pm 0.3$ vs. $5.0 \pm 0.1$ days). Expression of the molt-inhibiting hormone (mih) gene was upregulated in crabs reared under violet light. According to the regression analysis, maximum SGR would be at $449.97 \mathrm{~nm}$. Crabs exposed to blue light also had lower melatonin levels than under full-spectrum and lower cortisol levels than violet and yellow groups. Regarding oxidative stress, crabs in full-spectrum had lower $\mathrm{H}_{2} \mathrm{O}_{2}$ and MDA contents, however, no significant difference was found in total antioxidant capacity (T-AOC), superoxide dismutase (SOD), and catalase (CAT) in hepatopancreas from crabs under different spectra. Gene expression of hsp40, hsp70, hsp90 were down-regulated in crabs exposed to the full-spectrum light group. Regarding apoptosis-related genes, bcl-2 gene expression in crabs under cyan and the cox $I V$ and caspase 3 in green were upregulated, suggesting cyan light may inhibit, while green light may promote apoptosis. Taken together, these results suggest that blue or cyan light would promote growth performance, while full-spectrum light could reduce stress response in S. paramamosain.

Keywords: light spectrum, molting, oxidative stress, apoptosis, mud crab

\section{INTRODUCTION}

The mud crab (Scylla paramamosain) is a marine decapod crustacean species which plays a significant commercial and ecological role in marine aquaculture. Scylla paramamosain is widely distributed and farmed in Indo-West-Pacific, including south and southeastern China. S. paramamosain has been the most productive marine crab species cultured in China since 2009, 
and its output reached 159, $433 \mathrm{t}$ in 2020 (China FBOAMO, 2021). Nevertheless, due to the unreliability of the hatchery phase in aquaculture settings, the mud crab industry still highly relies on wild harvested mud crab juveniles, raising concerns over the sector's sustainability. Unreliable hatchery supply is mainly attributed to the lack of optimized and standardized husbandry protocols during early development leading to high mortality, and variable growth performances (Chen et al., 2021a).

Light, as an important environmental cue that influence growth performance, behavior, and physiology of aquatic animals (Gao et al., 2016a; Takahashi et al., 2018; Nasr et al., 2019; Yang et al., 2020), has three core elements, i.e., intensity, spectrum, and photoperiod. The visible spectrum is composed of shortwavelength (violet, $380-440 \mathrm{~nm}$ and blue, $440-485 \mathrm{~nm}$ ), middle wavelengths (green 500-565 nm and yellow, 565-590 nm), and long-wavelengths (orange, 590-625 nm and red, 625-740 nm) (Wu et al., 2021). Unlike terrestrial animals, photic conditions experienced by aquatic animals can be highly variable and depend on water properties including plankton, suspended particles, dissolved organic substances, and water depth acting as a chromatic filter (Mukai, 2011; Peng et al., 2019). In aquatic animals, understanding the impact of light and specifically spectrum on key physiological functions is complex and poorly characterized when compared to other abiotic factors. Studies performed in fish showed that shorter wavelengths (blue and green) can promote larvae growth performance in Atlantic cod (Gadus morhua), turbot (Scophthalmus maximus), and European sea bass (Dicentrarchus labrax) (Villamizar et al., 2009; SierraFlores et al., 2016). In crustaceans, enhanced growth was reported in the giant freshwater prawn (Macrobrachium rosenbergii) when exposed to green as opposed to red light (Wei et al., 2021). However, specific growth rate (SGR) was enhanced in the Chinese shrimp Fenneropenaeus chinensis reared under natural light while SGR was suppressed under blue light (Wang et al., 2003). In shellfish, previous studies on abalone Haliotis discus have shown improved hatching and larvae growth under blue and green light (Gao et al., 2015) contrasting with positive effect of orange and red light reported on growth performance of juvenile $H$. discus (Gao et al., 2016a). Such contrasting results reported in the literature clearly illustrate the species and stage of development specific effects of spectrum on aquatic animals and most studies so far have been performed in fish.

The effect of light on aquatic vertebrate animals is thought to be mainly mediated through melatonin (N-acetyl-5-methoxytryptamine), the light perception hormone which is remarkably conserved across vertebrate phyla (Falcón et al., 2010). In fish, studies have suggested that melatonin is involved in the circadian and seasonal entrainment of many essential physiological functions (Falcón et al., 1992; Oliveira et al., 2007). However, light regulation of pineal melatonin production diverged in teleost species as a result of evolution and striking differences in spectral sensitivities were reported between species (Migaud et al., 2007a; Vera et al., 2010). In crustaceans, light perception and transduction has not been studied much and while melatonin is mainly secreted by the eyestalks, it has also been detected in the hemolymph and nervous systems (Pape et al., 2008; Zhang et al., 2018). Melatonin was reported to impact on a range of biological processes in crustaceans including glucose metabolism, oxidative stress, limb regeneration, and molting (Sainath and Reddy, 2010a,b; Sainath et al., 2013; Girish et al., 2015). A recent study from our laboratory showed melatonin levels in the eyestalks of $S$. paramamosain were significantly affected by light intensity (Chen et al., 2021a), however, light spectral effects remain unknown in the species.

Many biological functions (e.g., reproduction, metabolism, growth, behavior) and life transition events (e.g., spawning, hatching, metamorphosis, smoltification) in fish are regulated by environmental signals including light with strong relevant applications to the sector. In crustaceans, molting is particularly interesting as it directly controls the growth of the animals (Kobayashi, 2012; Yang et al., 2018). Crustaceans molting is mainly controlled by ecdysteroids and molt-inhibiting hormone (MIH) secreted by the Y-organs and the complex X-organ-sinus gland (XO-SG) (Imayavaramban et al., 2007). The fundamental function of $\mathrm{MIH}$ is to suppress ecdysteroid biosynthesis to regulate molting (Qiao et al., 2018). Molting, and subsequently growth, in crab species are also regulated by many abiotic factors including temperature (Yuan et al., 2017), salinity (Gong et al., 2015), and light intensity (Li et al., 2011; Chen et al., 2021a). Previous studies indicated that light fluctuations from blue to green or yellow spectra could promote growth and molting frequency of L. vannamei (Guo et al., 2011). In contrast, the effect of light spectrum on mud crab molting remains little studied.

Oxidative stress is another critical function in animals which is impacted by external factors. The reactive oxygen species (ROS) such as superoxide anion radical $\left(\mathrm{O}^{2-}\right)$, hydroxyl radical $\left(\mathrm{OH}^{-1}\right)$, and hydrogen peroxide $\left(\mathrm{H}_{2} \mathrm{O}_{2}\right)$ are produced as a result of metabolism and immune defense response in cells (Bogdan et al., 2000; Kohen and Nyska, 2002). Excessive accumulation of ROS may result in oxidative stress, cellular damage, and ultimately compromise cell functions (Guo $\mathrm{H}$. et al., 2013; Guo Z.-X. et al., 2013; Cheng et al., 2020). In response to ROS, animals have evolved various antioxidant enzymes such as superoxide dismutase (SOD), catalase (CAT), and peroxiredoxins (Prx) to counteract oxidation (Chen et al., 2021b). Light spectrum have been suggested to influence the antioxidant capacity of aquatic organisms as reported in abalone (Haliotis discus hannai) (Gao et al., 2016b), whiteleg shrimp (Penaeus vannamei) (Fei et al., 2020a), and turbot (Scophthalmus maximus) (Wu et al., 2021). Furthermore, as an end-product of lipid peroxidation, malondialdehyde (MDA) is used as an indicator of oxidative damage in organisms (Liu et al., 2011). Recent studies have demonstrated that ROS and the resulting oxidative stress play a pivotal role in activating apoptosis (Kannan and Jain, 2000). Apoptosis plays an essential role in removing the excess, damaged, necrotic, and potentially dangerous cells (Wyllie et al., 1980). The expression levels of apoptosis-related genes such as $b c l-2, p 53$, and caspase 3 can be used as biomarkers of tissue apoptosis. A recent study showed that exposure to dark condition suppressed apoptosis-related gene expression in Litopenaeus vannamei (Fei et al., 2020a). In addition, gene expression of bcl-2, p53, and cytochrome $c$ in the hepatopancreas of $L$. vanname $i$ was significantly reduced in shrimp reared under a full spectrum + UVA and full spectrum + UVB (Fei et al., 2020b). 
In the present study, the Light Emitting Diodes (LED) were used to create seven different light spectra to investigate the effects of light spectrum on growth, molting, antioxidant capacity, and apoptosis-related gene expression in the mud crab S. paramamosain. The overall goal of this work is to identify optimal environmental conditions for S. paramamosain produced in land-based hatcheries and nurseries to boost juvenile outputs, performance and reduce the reliance of the sector on wild-harvested stocks.

\section{MATERIALS AND METHODS}

\section{Experimental Animal, Rearing Conditions, and Experimental Design}

A total of 273 juvenile mud crab (Initial weight: $12.05 \pm 2.15 \mathrm{mg}$ ) were obtained from Choupijiang farm (Ningbo City, Zhejiang province, China) and transferred to the experimental tanks on the Meishan campus of Ningbo University. Crabs were randomly distributed into seven treatments in triplicates $(13$ crabs per replicate, 39 per treatment). Crabs were individually stocked in polypropylene containers $(14.1 \mathrm{~cm} \times 8.4 \mathrm{~cm} \times 5.0 \mathrm{~cm})$ with $750 \mathrm{~mL}$ of seawater. During the experiment, formulated diet with crude protein $\geq 40.0 \%$, crude lipid $\geq 6.0 \%$, and crude fiber $\leq 5.0 \%$ (Ningbo Tech-Bank Feed Co., Ltd., Ningbo, China) was given once daily at 17:00, and $100 \%$ rearing water was changed daily at 08:00 am. During the experiment, the water temperature was maintained at $26 \pm 1^{\circ} \mathrm{C}$, salinity $24 \pm 1 \mathrm{ppt}$, ammonia and nitrite $<0.5 \mathrm{mg} \mathrm{L}^{-1}$ (HACH, 2604545 and 2608345, respectively), and dissolved oxygen $>6.0 \mathrm{mg} \mathrm{L}^{-1}$ (Proplus, YSI, Yellow Springs, Ohio, United States).

Seven LED lamps (Institute of Semiconductors, Chinese Academy of Sciences, Semiconductor Lighting R\&D Center) with specific narrow bandwidths were used in the experiment. The light intensity and light spectrum (Figure 1) in each treatment were measured by a spectroradiometer (PLA20 Plant Lighting Analyzer, Hangzhou, China). Peak and full width at half maximum (FWHM) wavelengths for the seven treatments were 634.4/233.4 $\mathrm{nm}$ (full-spectrum), $400.7 / 12.4 \mathrm{~nm}$ (Violet), 460.0/20.2 nm (Blue), 510.4/33.7 nm (Cyan), 518.5/34.1 nm (Green), 576.5/15.8 nm (Yellow), and 619.7/23.8 $\mathrm{nm}$ (Red), respectively. Systems were light proofed using black clothes to prevent light pollution between treatments. The light intensity was set at $1 \mathrm{~W} \mathrm{~m}^{-2}$ by adjusting dimmers and the distance between lamps and the water surface. The photoperiod was set as 12L:12D (photophase between 6:00 and 18:00).

\section{Sampling and Data Calculations}

The final weight $\left(\mathrm{W}_{f}\right)$, carapace width $(\mathrm{CW})$, carapace length (CL), and body height $(\mathrm{BH})$ of all living crabs were measured after $24 \mathrm{~h}$ starvation at the end of the experiment (8 weeks). The hepatopancreas and eyestalks were collected and snap frozen in liquid nitrogen. Samples were stored at $-80^{\circ} \mathrm{C}$ for subsequent analysis.
The number of days between two consecutive molts was monitored as the molting interval. Survival rate, weight gain, SGR, molting interval, and molting frequency were calculated using the following equations:

$$
\begin{gathered}
\text { Survival rate }(\mathrm{SR}, \%)=\left(\mathrm{N}_{\mathrm{t}}-\mathrm{N}_{\mathrm{i}}\right) / \mathrm{N}_{\mathrm{i}} \times 100 \\
\text { Weight gain }(\mathrm{WG}, \%)=\left(\mathrm{W}_{\mathrm{f}}-\mathrm{W}_{\mathrm{i}}\right) / \mathrm{W}_{\mathrm{i}}
\end{gathered}
$$

Specific growth rate $\left(\mathrm{SGR}, \%\right.$ day $\left.^{-1}\right)=100 \times\left(\mathrm{Ln} \mathrm{W}_{\mathrm{f}}-\mathrm{Ln} \mathrm{W}_{\mathrm{i}}\right) / \mathrm{t}$

$$
\text { Condition factor } \left.(\mathrm{CF})=100^{*} \text { (body weight } / \mathrm{CL}^{3}\right)
$$$$
\text { Molting frequency }(\mathrm{MF})=\Sigma\left(\left(\mathrm{C}_{\mathrm{n}}-1\right) \times \mathrm{N}_{\mathrm{n}}\right) / \mathrm{N}_{\mathrm{t}}
$$

Molting interval $(\mathrm{MI}$, days $)=$ Date $\left(\mathrm{C}_{\mathrm{n}}\right)-$ Date $\left(\mathrm{C}_{\mathrm{n}-1}\right)$

Where $\mathrm{N}_{t}$ is the number of crabs at the beginning of the experiment; $\mathrm{N}_{i}$ is the number of crabs at the end of the experiment, $\mathrm{W}_{f}$ is final body weight in gram; $\mathrm{W}_{i}$ is initial body weight in gram, and the " $\mathrm{t}$ " is the experimental duration (days); $\mathrm{N}_{n}$, the number of molting stages; $\mathrm{N}_{t}$, the total number of survival crabs; $\mathrm{C}_{n}$, the developmental stage of crab.

\section{Analysis of Antioxidant Capacity}

Samples ( $n=3,6$ hepatopancreas per treatment) were homogenized in ice-cold normal saline and centrifuged at $825 \mathrm{~g} \mathrm{~min}^{-1}$ at $4^{\circ} \mathrm{C}$ for $15 \mathrm{~min}$. The activity of superoxide dismutase (SOD, A001-3-2, Jiancheng, Nanjing, China) was measured by WST-1 method (Peskin and Winterbourn, 2000). Catalase (CAT, A007-1-1, Jiancheng, Nanjing, China) was tested using the hydrogen peroxide decomposition method (Góth, 1991). Total antioxidant capacity (T-AOC, A015-2-1, Jiancheng, Nanjing, China) was assessed via the ABTS method (Re et al., 1999). Malondialdehyde concentration (MDA, A003-1-2, Jiancheng, Nanjing, China) was measured by thiobarbituric acid (TBA) reaction (Ohkawa et al., 1979). Finally, hydrogen peroxide $\left(\mathrm{H}_{2} \mathrm{O}_{2}\right)$ was tested using commercial kits (Nanjing Jiancheng Bioengineering Institute, Nanjing, China). All the above analyses have been validated previously for S. paramamosain (Xu et al., 2019).

\section{Measurement of Melatonin and Cortisol}

The eyestalks from each treatment $(n=3,6$ individuals per treatment) were homogeneized and dissolved in PBS. After centrifuging at $825 \mathrm{~g}$ at $4^{\circ} \mathrm{C}$ for $15 \mathrm{~min}$, the supernatant was collected to analyze melatonin and cortisol contents. Sample analyses were performed using crab's specific melatonin and cortisol ELISA kits supplied by Enzyme-linked Biotechnology (Qiaodu-Bio, Shanghai, China). Kits have been validated previsouly in S. paramamosain (Chen et al., 2021a). Detection limit was $1 \mathrm{pg} \mathrm{mL}^{-1}$, and both intra-assay and inter-assay coefficients of variation for both kits were less than $15 \%$. 


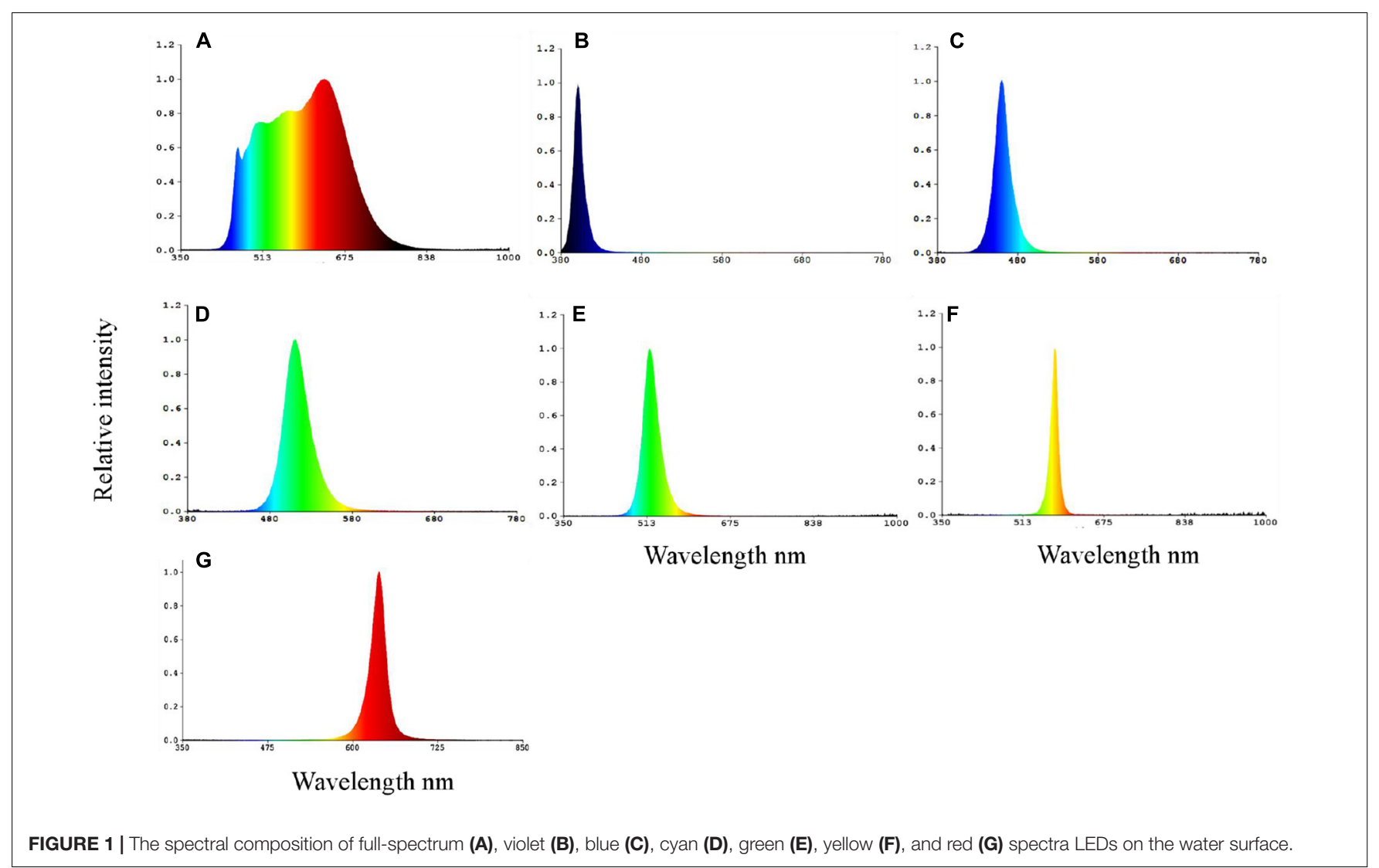

\section{RNA Extraction, cDNA Synthesis, and Quantitative PCR Analysis}

Trizol Reagent (Invitrogen, United States) was used to extract the total RNA from hepatopancreas samples according to manufacturer instructions. The quality and quantity of the RNA was assessed by electrophoresis and was measured with a small volume spectrophotometer (Eppendorf NanoDrop 2000). The RNA pellet was eluted in $20 \mu \mathrm{L}$ of nucleasefree water prior to cDNA synthesis using HiFiScript cDNA Synthesis Kit (CW Biotech. Co., Lid., Shanghai, China) with $2 \mu \mathrm{g}$ RNA. The synthesized cDNA stored at $-80^{\circ} \mathrm{C}$ until use.

Real-time PCR assays were carried out in a Lightcycler 96 (Roche) using SYBR green as a fluorescent dye. The primers used for Quantitative PCR (qPCR) are listed in Table 1. The qPCR amplifications were carried out in total reaction volumes of 20 $\mu \mathrm{L}$, which included $10 \mu \mathrm{L}$ of SYBR green mixed reagent [Magic SYBR Mixture (CW3008H), CW Biotech. Co., Lid., Shanghai, China], $1 \mu \mathrm{L}$ of each of the forward and reverse primers, 1 $\mu \mathrm{L}$ of cDNA template and $7 \mu \mathrm{L}$ of $\mathrm{ddH}_{2} \mathrm{O}$. All detection for each sample was performed twice. The procedure of quantitative PCR contained an initial activation step at $95^{\circ} \mathrm{C}$ for $2 \mathrm{~min}$, followed by 45 cycles of $95^{\circ} \mathrm{C}$ for $10 \mathrm{~s}$ and $55^{\circ} \mathrm{C}$ for $10 \mathrm{~s}$, and $72^{\circ} \mathrm{C}$ for $20 \mathrm{~s}$. To verify that the primer pair produced a single product, the dissociation curve of the product was also tested by heating from 55 to $95^{\circ} \mathrm{C}$ at the end of the reaction. The molting inhibiting hormone $(m i h)$, heat shock protein 40,70 , and 90 ( $h s p 40, h s p 70$, and $h s p 90)$, tumor suppressor protein p53 ( $p 53)$, bcl-2, caspase-3, and cytochrome $c$ oxidase IV (cox IV) were normalized with $\beta$-actin used as the housekeeping gene. Target genes' critical threshold $(\mathrm{Ct})$ quantities were standardized with quantities of housekeeping gene using the optimized comparative $2^{-\Delta} \Delta C T$ method (Livak and Schmittgen, 2001), and the results were presented as $\mathrm{n}$-fold changes relative to the housekeeping gene.

\section{Data Calculations and Statistical Analysis}

All data are presented as the mean \pm standard deviation (mean \pm SD). Data were analyzed using SPSS 25.0 statistical software. The normality and homogeneity were checked by Kolmogorov-Smirnov test and Levene's test, respectively. The normal distributed and homogenous data were compared with one-way ANOVA and Tukey's post hoc multiple comparisons. Non-parametric tests, including the Kruskal-Wallis test, Mann-Whitney test, and Bonferroni correction, were performed to compare SR (after being subjected to arcsine square-root transformation), molting frequency, and molting interval. Bonferroni correction was used for multiple comparisons. To determine the relationship between wavelength, growth, and molting, the Pearson correlation analysis was performed and $t$-test were used. A significance of $P<0.05$ was applied to all statistical tests. 
TABLE 1 | Primers used for QPCR in this study.

\begin{tabular}{|c|c|c|c|}
\hline Gene & Sequence $\left(5^{\prime}-3^{\prime}\right)$ & $\operatorname{Tm}\left({ }^{\circ} \mathrm{C}\right)$ & $\begin{array}{l}\text { References or } \\
\text { accession } \\
\text { number }\end{array}$ \\
\hline \multirow[t]{2}{*}{$\beta$-actin } & F: GAGCGAGAAATCGTTCGTGAC & 56 & Xu et al., 2019 \\
\hline & R: GGAAGGAAGGCTGGAAGAGAG & & \\
\hline \multirow[t]{2}{*}{$\operatorname{mih}$} & F: CCGCGCTAACTCCAGATTIT & 57 & JQ855710.2 \\
\hline & R: TTGCCAGTATCGGTGTGAGA & & \\
\hline \multirow[t]{2}{*}{ hsp40 } & F: CATTGACTGAAAGTGCGAAAG & 55 & JQ864186.1 \\
\hline & R: AAACGGATGTCCACCCAAG & & \\
\hline \multirow[t]{2}{*}{ hsp70 } & F: CAACAGAACTACGCCCTCC & 57 & EU754021.1 \\
\hline & R: AATCAGCCTCTTGGCATCA & & \\
\hline \multirow[t]{2}{*}{ hsp90 } & F: AAGCGTATGACTTTGTGGA & 54 & JX987068.1 \\
\hline & R: CTTCTTCGTCTTGGGTTG & & \\
\hline \multirow[t]{2}{*}{$p 53$} & F: AAGCAAGTCAATGAACGCTATGTG & 55 & $\begin{array}{l}\text { Cheng et al., } \\
2020\end{array}$ \\
\hline & R: AATGGGCTGCGAAGGACG & & \\
\hline \multirow[t]{2}{*}{ caspase 3} & F: ACGAAGTGAGGGGATTATGCC & 55 & \\
\hline & R: CAGCCCATCCAGCGAGC & & \\
\hline \multirow[t]{2}{*}{$b c l-2$} & F: GAAGTGGACCTGGAAAGTAA & 55 & MK426684.1 \\
\hline & R: GCTCACAGGGAGAAGCATAG & & \\
\hline \multirow{2}{*}{$\begin{array}{l}\text { Cytochrome } c \\
\text { oxidase IV } \\
(\operatorname{cox} M)\end{array}$} & F: GGCGAGGAAGGGATAC & 55 & FJ774694.1 \\
\hline & R: GGAAGTCAACACGGTCATA & & \\
\hline
\end{tabular}

\section{RESULTS}

\section{Survival, Growth, and Molting}

Survival rates in the blue and cyan groups were significantly higher than in the yellow and violet groups but was not significantly different than in the full-spectrum, green and red groups (Figure 2A). Crabs reared under violet had significantly lower $\mathrm{W}_{f}$ and $\mathrm{WG}$ than the blue group (Figures 2B,C). No significant differences in $\mathrm{W}_{f}$ and $\mathrm{WG}$ were detected between full-spectrum, blue, red, yellow, green, and cyan groups. The coefficient of variation for weight gain $\left(\mathrm{CV}_{W G}\right)$ was higher in the full-spectrum group $(41.1 \pm 10.6 \%)$ than violet group $(18.7 \pm 8.1 \%)$, but not significantly different than any other groups (Figure 2D). The relationship between light wavelength and SGR based on a 4-parameter saturation kinetic models (4-SKM) showed maximum SGR for spectrum of $449.97 \mathrm{~nm}$ $\left(R^{2}=0.5961\right)$ (Figure 3). No significant differences were detected in $\mathrm{CW}$ and $\mathrm{BH}$ between treatments (Table 2). However, CL was significantly influenced by light spectrum, with crabs reared under a blue light showing a higher CL than under violet. In addition, there was no significant differences in CF between treatments (Table 2).

Crabs reared under full-spectrum and cyan light had a higher molting frequency than yellow and violet (Figure 4A). No significant differences were detected in the molting interval (C2$\mathrm{C5})$. However, significant differences in molting interval (C1-C2) and molting interval (C5-C6) were detected between treatments (Figures 4B-F). The molting interval from $\mathrm{C} 1$ to $\mathrm{C} 2$ in the violet group increased significantly compared to full-spectrum and blue groups, but was not significantly different to any other groups (Figure 4B). For crabs of, A higher molting interval from C5 to C6 was detected in blue and red groups, which was significantly higher than for violet and yellow groups.

\section{Melatonin and Cortisol}

Melatonin levels in the eyestalks of crabs exposed to fullspectrum were significantly higher than for blue, cyan, and yellow groups but not significantly different from violet, green, and red
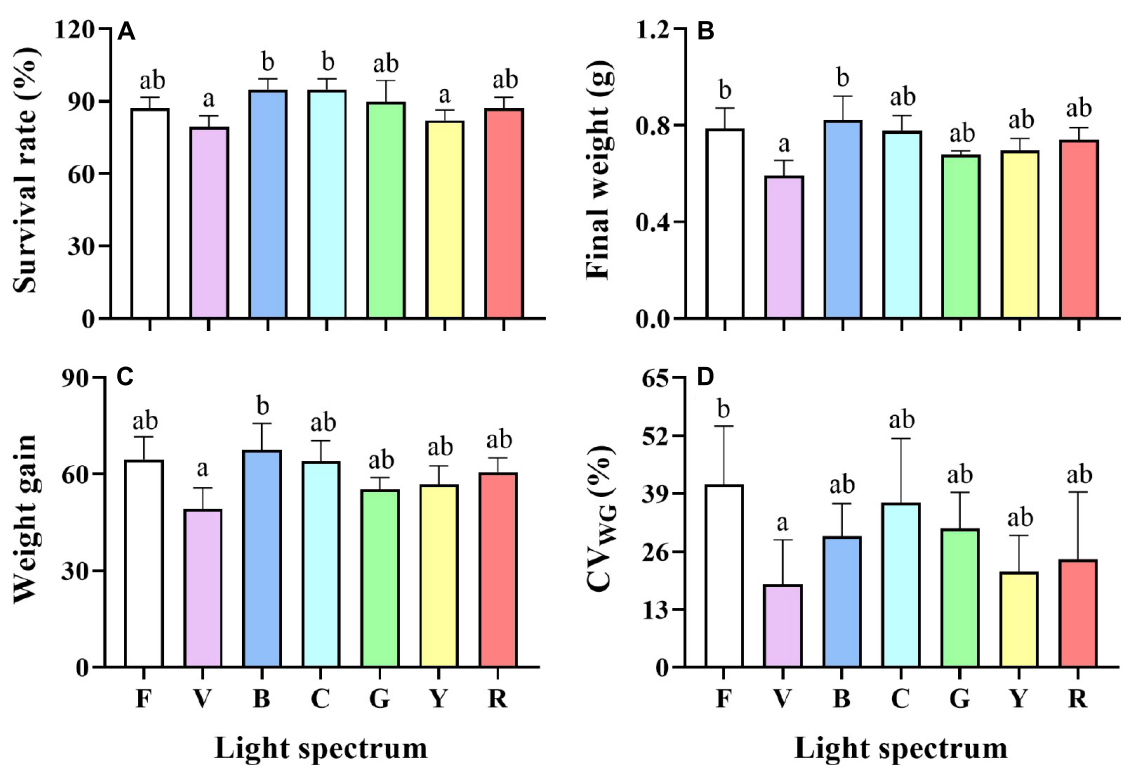

FIGURE 2 | Survival rate (A), Final weight (B), Weight gain (C), coefficient of variation of weight gain (D) of S. paramamosain reared under the different spectra. Values are expressed as means \pm SD $(n=3)$. F, Full spectrum; V, Violet; B, Blue; C, Cyan; G, Green; Y, Yellow; R, Red. Different superscripts denote significant differences between treatments $(P<0.05)$. 
TABLE 2 | Morphology indexes of S. paramamosain reared under different light spectra during 8 weeks, including final carapace length $(C L)$ and width $(C W)$, body height $(\mathrm{BH})$, and condition factor $(\mathrm{CF})$.

\begin{tabular}{lcccc}
\hline Treatments & CL (cm) & CW (cm) & BH (cm) & CF \\
\hline Full spectrum & $1.61 \pm 0.08$ & $1.14 \pm 0.05^{\mathrm{ab}}$ & $0.61 \pm 0.03$ & $19.01 \pm 2.32$ \\
Violet $(405 \mathrm{~nm})$ & $1.46 \pm 0.11$ & $1.03 \pm 0.06^{\mathrm{a}}$ & $0.56 \pm 0.02$ & $19.27 \pm 2.77$ \\
Blue $(470 \mathrm{~nm})$ & $1.62 \pm 0.09$ & $1.16 \pm 0.07^{\mathrm{b}}$ & $0.63 \pm 0.05$ & $19.16 \pm 0.96$ \\
Cyan $(500 \mathrm{~nm})$ & $1.49 \pm 0.03$ & $1.08 \pm 0.02^{\mathrm{ab}}$ & $0.57 \pm 0.01$ & $23.63 \pm 2.92$ \\
Green $(525 \mathrm{~nm})$ & $1.51 \pm 0.04$ & $1.07 \pm 0.02^{\mathrm{ab}}$ & $0.56 \pm 0.02$ & $19.89 \pm 1.16$ \\
Yellow $(570 \mathrm{~nm})$ & $1.51 \pm 0.08$ & $1.08 \pm 0.04^{\mathrm{ab}}$ & $0.58 \pm 0.03$ & $20.52 \pm 1.78$ \\
Red $(625 \mathrm{~nm})$ & $1.56 \pm 0.04$ & $1.11 \pm 0.01^{\mathrm{ab}}$ & $0.60 \pm 0.01$ & $19.64 \pm 0.67$ \\
\hline
\end{tabular}

Values are expressed as the means $\pm S D(n=3$ replicate, and $34,31,37,37$, 35,32 , and 34 per treatment). Different superscripts denote significant differences between treatments $(P<0.05)$.

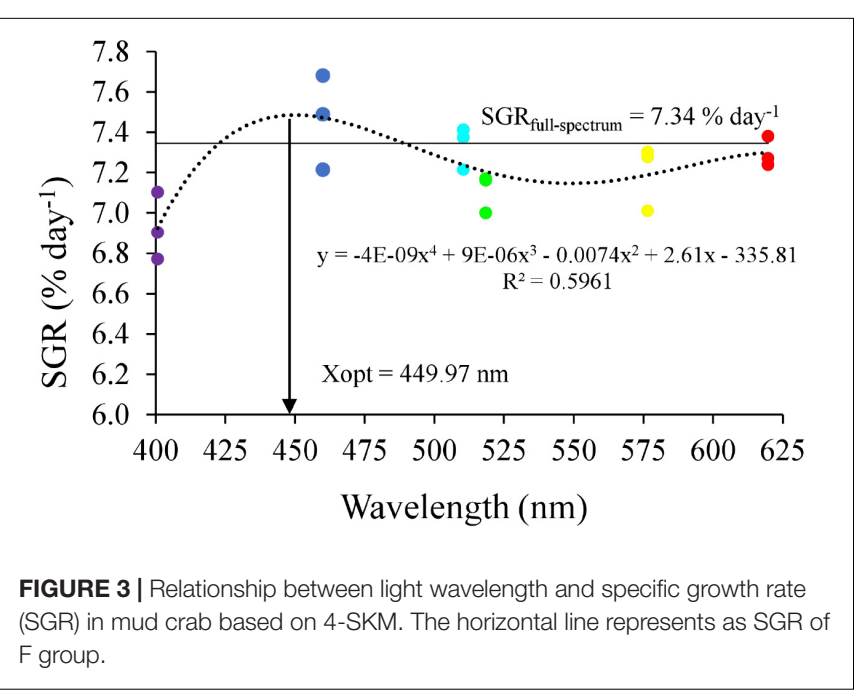

groups (Figure 5A). Cortisol levels increased in violet and yellow groups compared to blue light treatment, while no significant difference was detected between full-spectrum, cyan, green, and red groups (Figure 5B).

\section{Antioxidant Capacity}

Antioxidant capacity was significantly impacted by light spectrum (Figure 6). No significant differences were detected in T-AOC levels, SOD, and CAT activities in the hepatopancreas of crabs under different spectra. However, significant differences in $\mathrm{H}_{2} \mathrm{O}_{2}$ and MDA contents were detected between treatments (Figures 6D,E). The $\mathrm{H}_{2} \mathrm{O}_{2}$ content in crabs exposed to violet light $\left(239.6 \pm 23.1 \mathrm{U}\right.$ gprot $\left.^{-1}\right)$ was significantly higher than in the green light $\left(153.2 \pm 24.8 \mathrm{U} \mathrm{mgprot}^{-1}\right)$. Crabs from red $\left(11.1 \pm 0.6 \mathrm{mmol} \mathrm{mgprot}^{-1}\right)$, violet $(10.5 \pm 1.3 \mathrm{mmol}$ mgprot $\left.^{-1}\right)$, and blue $\left(9.1 \pm 0.6 \mathrm{mmol} \mathrm{mgprot}^{-1}\right)$ groups had higher MDA content than full-spectrum group $(5.0 \pm 0.8 \mathrm{mmol}$ $\operatorname{mgprot}^{-1}$ ).

\section{Gene Expression}

\section{Molt-Inhibiting Hormone in Eyestalks}

The relative expression of mih gene in eyestalks of crabs reared under violet and yellow groups were significantly higher than in all other treatments. No significant difference was detected between full-spectrum, blue, cyan, green, and red groups (Figure 7).

\section{Heat Shock Protein Genes in Hepatopancreas}

Light spectrum affected the relative mRNA gene expression of $h s p 40, h s p 70$, and $h s p 90$ measured in S. paramamosain hepatopancreas (Figure 8). The relative expression levels of $h s p 40$ in the violet group were significantly higher than in the other groups (Figure 8A). The relative expression levels of $h s p 70$ in the blue and yellow groups were significantly higher than in the other groups except for cyan p (Figure 8B). The expression of $h s p 90$ was significantly higher in blue compared to full spectrum and violet groups (Figure 8C).

\section{Apoptosis Related Genes in Hepatopancreas}

Significant differences were found in the relative expression levels of $b c l-2$ between treatments. Compare to the full-spectrum and violet groups, $b c l-2$ was significantly upregulated in crabs exposed to cyan light (Figure 9A). The relative expression levels of $p 53$ were not significantly different between treatments (Figure 9B). Relative expression levels of cox $I V$ were also significantly influenced by light spectrum with the highest expression levels detected in the green group, which was significantly higher than all other groups except cyan group (Figure 9C). Expression levels of caspase 3 were significantly higher in crabs reared under green light than in all other groups (Figure 9D).

\section{Correlation Analysis}

Correlations between wavelength and growth (WG), molting (MF), relative expression of mih and oxidative stress $\left(\mathrm{H}_{2} \mathrm{O}_{2}\right.$ and MDA) parameters were analyzed by Pearson correlation coefficient (Figure 10). $\mathrm{H}_{2} \mathrm{O}_{2}$ content was negatively correlated with wavelength $\left(R^{2}=-0.647, p=0.004\right)$, while $\mathrm{WG}$ was significantly positively correlated with molting frequency $\left(R^{2}=0.703, p=0.001\right)$ and negatively correlated with the relative expression of mih $\left(R^{2}=-0.592, p=0.01\right)$ (Figure 10). In addition, the relative expression of $\mathrm{mih}$ was negatively correlated with molting frequency $\left(R^{2}=-0.495, p=0.037\right)$.

\section{DISCUSSION}

In aquaculture, most research on the effects of light have been performed in fish with less studies done in invertebrates and especially crustaceans. Results from the current study showed that crabs reared under blue $(460 \mathrm{~nm})$ and cyan $(510 \mathrm{~nm})$ narrow bandwidth lights grew significantly better than for any other spectra tested, especially violet and yellow. Additionally, higher molting performance and lower oxidative stress and apoptosis were observed in the blue groups. The 4-SKM showed that the optimal light wavelength for maximum SGR in mud crab was $449.97 \mathrm{~nm}$.

Published studies suggested that light spectrum can affect the feeding behavior of crabs impacting on feeding efficiency and growth (Cohen and Forward, 2002; Luchiari et al., 2009). However, contrasting results have been reported in the literature 
A

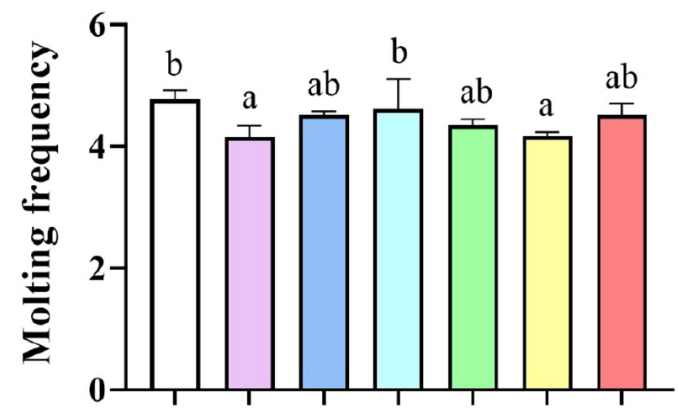

C
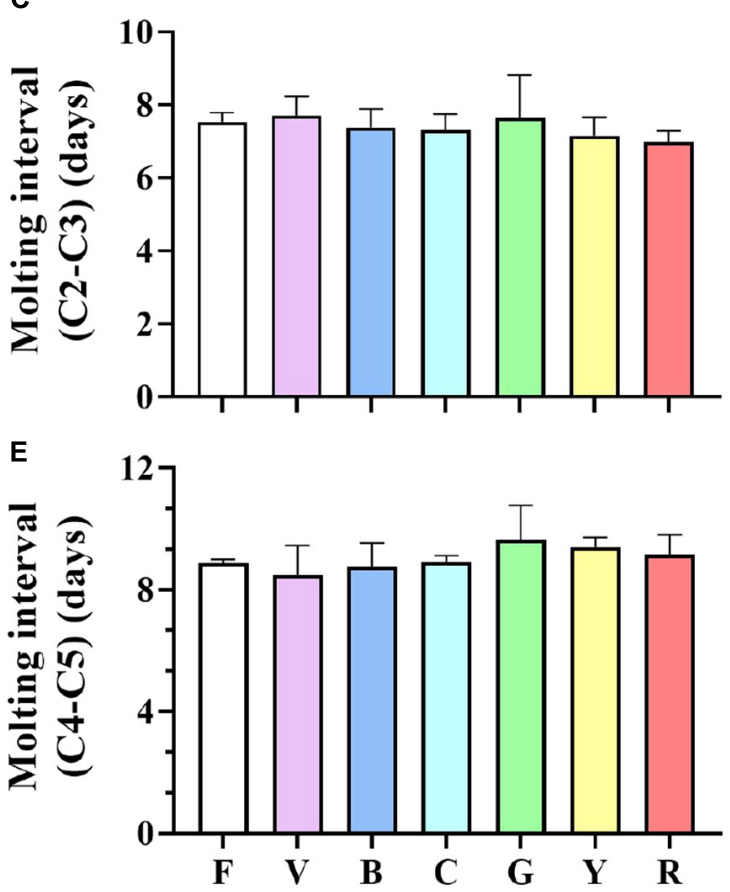

Light spectrum

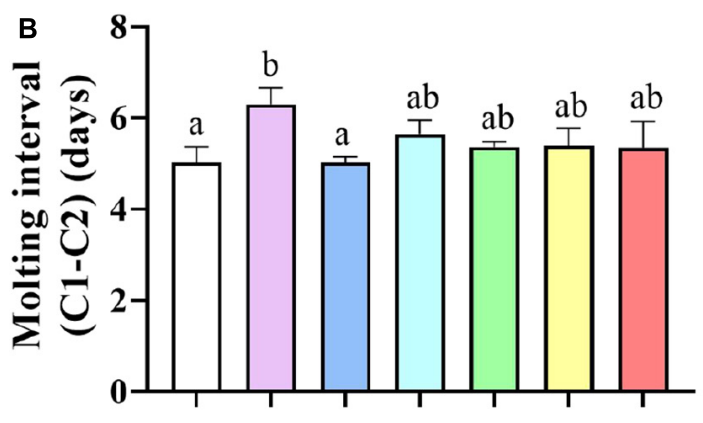

D
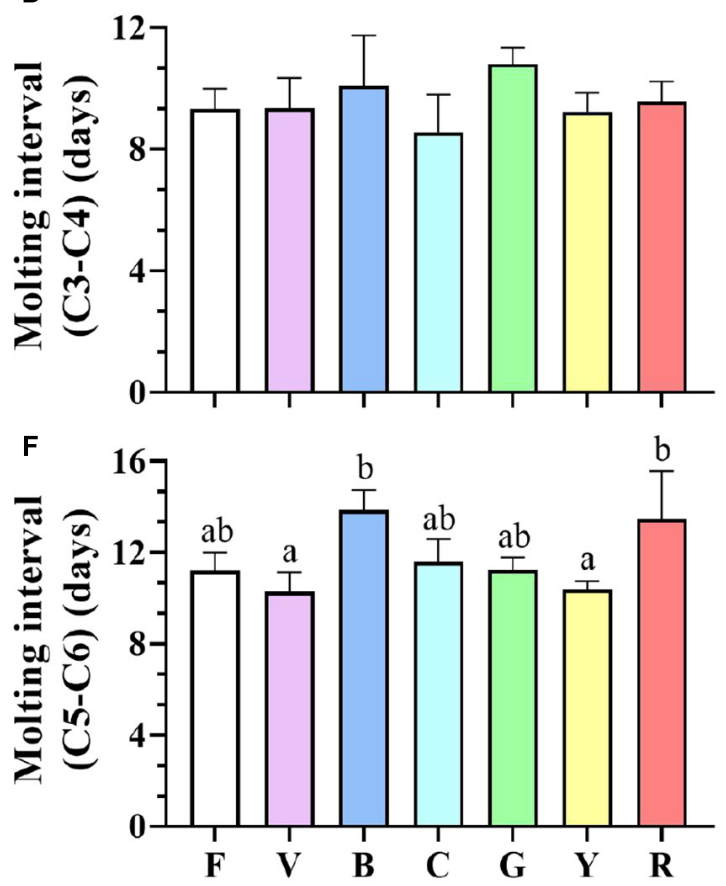

Light spectrum

FIGURE 4 | Molting frequency (A), Molting interval (C1-C2) (B), Molting interval (C2-C3) (C), Molting interval (C3-C4) (D), Molting interval (C4-C5) (E) and Molting interval (C5-C6) (F) of S. paramamosain reared under the different spectra. Values are expressed as means $\pm S D(n=3$, all survival crab per replicate). $F$, Full spectrum; V, Violet; B, Blue; C, Cyan; G, Green; Y, Yellow; R, Red. Different superscripts denote significant differences between treatments ( $>$ <.05).

and the relationship between the animal spectral sensitivity and its behavior, depending on its stage of development, is not well understood. Spectral sensitivity of mud crab Scylla serrata was shown to peak at around $500 \mathrm{~nm}$ (Yang et al., 1985). A study in the swimming crab (Portunus trituberculatus) suggested that crabs are more sensitive to yellow and red light by looking at the microvillus of photoreceptors and number of organelles (Luo et al., 2006). However, a growth experiment showed feeding rate was suppressed in $P$. trituberculatus exposed to yellow light in contrast to blue which appeared to promote feeding but surprisingly growth did not correlate with feeding response (Wang et al., 2014). The visual sensitivity, background color preference, and growth and development are clearly not consistent, as observed in P. trituberculatus larvae (Shi et al., 2019) but also in fish species like barramundi (Lates calcarifer) (Ullmann et al., 2011). Light perception, sensitivity and biological efficiency change during the ontogenic development of any species and in crabs, it was suggested that juveniles may rely more on chemoreception to locate and identify their preys rather than light at the larval stage (Zimmer-Faust, 1989). This would explain mismatches reported between light sensitivity and physiological effects such as feeding and growth response. Growth effects identified under specific light conditions may be mediated through changes in feed conversion ratio as reported in fish species rather than feeding rate (Taylor et al., 2006; Karakatsouli et al., 2010). Characterizing the effect of light spectrum on crustacean physiology is therefore complex and will depend on species, stage of development but also light irradiance and photoperiod.

In the present study, the highest molting frequency was found in full-spectrum and cyan groups. The relative expression of $\mathrm{mih}$ gene was significantly upregulated in violet and yellow groups 

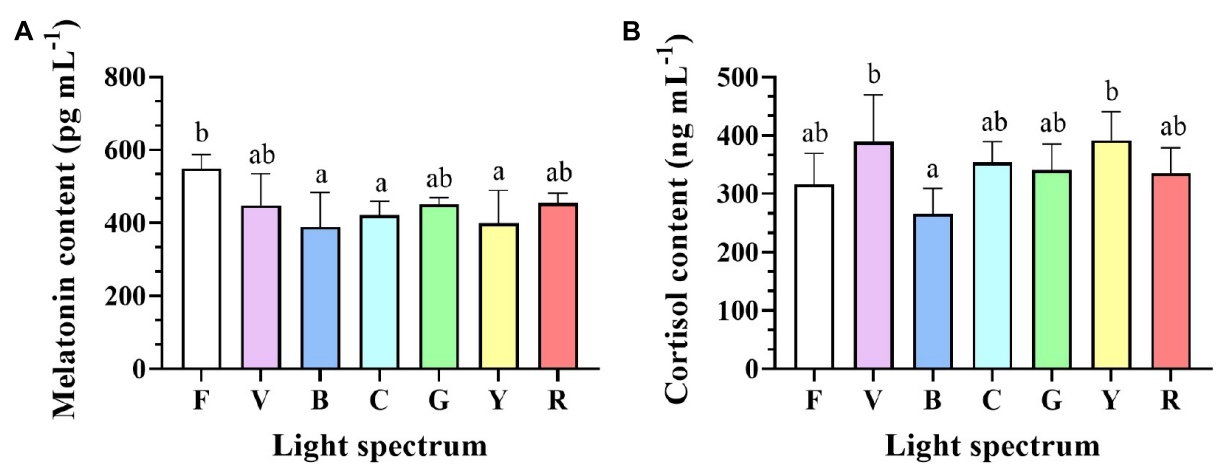

FIGURE 5 | Melatonin (A) and cortisol (B) levels in eyestalks of $S$. paramamosain reared under various light spectrum. Values are expressed as means \pm SD $(n=3$, 2 individuals per replicate). F, Full spectrum; V, Violet; B, Blue; C, Cyan; G, Green; Y, Yellow; R, Red. Different superscripts denote significant differences between treatments $(P<0.05)$.
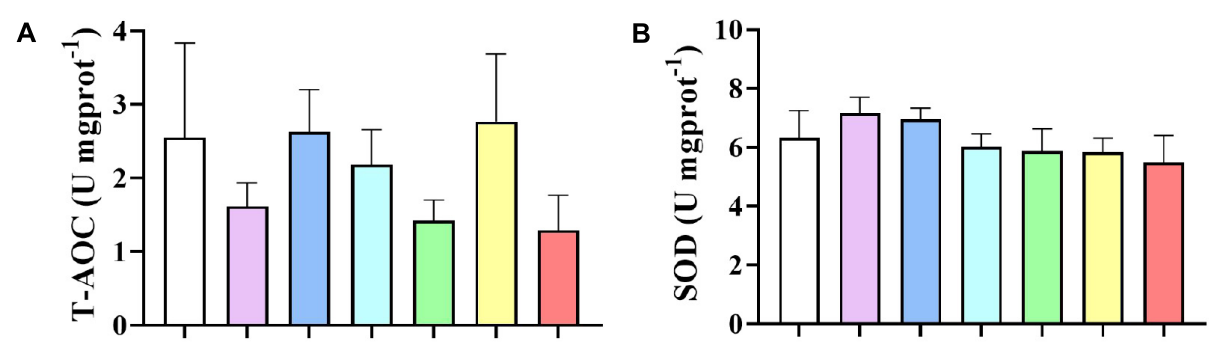

C

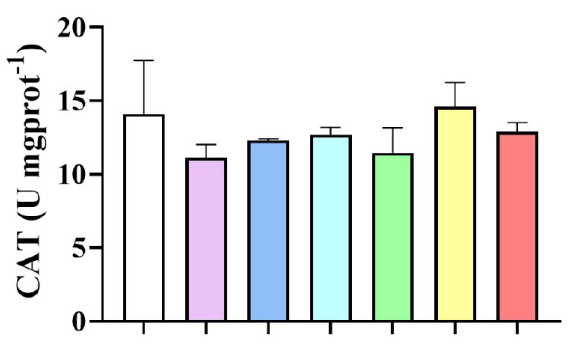

E

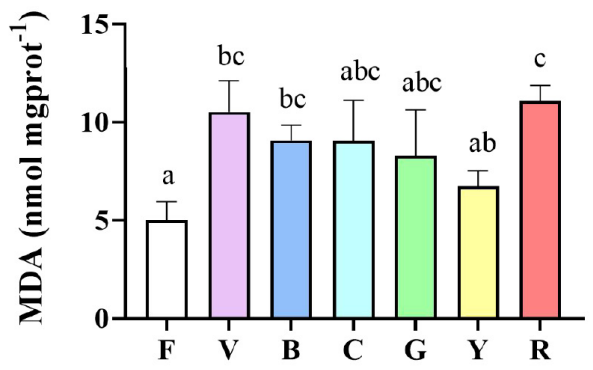

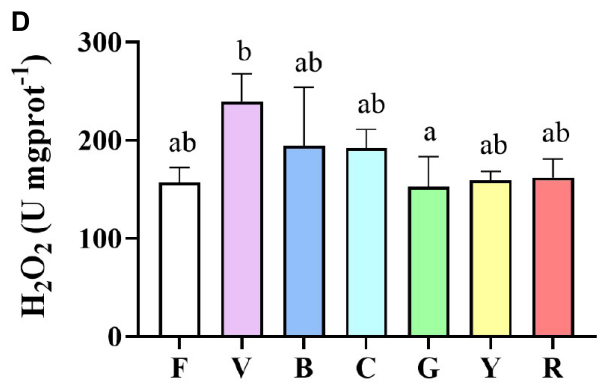

Light spectrum

Light spectrum

FIGURE 6 | The total antioxidant capacity (T-AOC) (A), superoxide dismutase (SOD) (B), catalase (CAT) (C), hydrogen peroxide ( $\left.\mathrm{H}_{2} \mathrm{O}_{2}\right)$ (D) and malondialdehyde (MDA) (E) contents in the hepatopancreas of $S$. paramamosain reared under the various light spectrum. Values are expressed as means \pm SD $(n=3,2$ individuals per replicate). F, Full spectrum); V, Violet; B, Blue; C, Cyan, G, Green; Y, Yellow; R, Red. Different superscripts denote significant differences between treatments $(P<0.05)$.

(3.1- and 2.4-fold, respectively, compared to full-spectrum group), and these two groups had the lowest molting frequency, suggesting spectrum may play an important role in growth by regulating molting in crabs. Similar results were also observed in Litopenaeus vannamei, with higher molting frequency in shrimp exposed to green rather than blue light (Guo et al., 2011). Molting in crustaceans can also be suppressed by stress factors (Mykles et al., 2010). The highest cortisol levels found in 


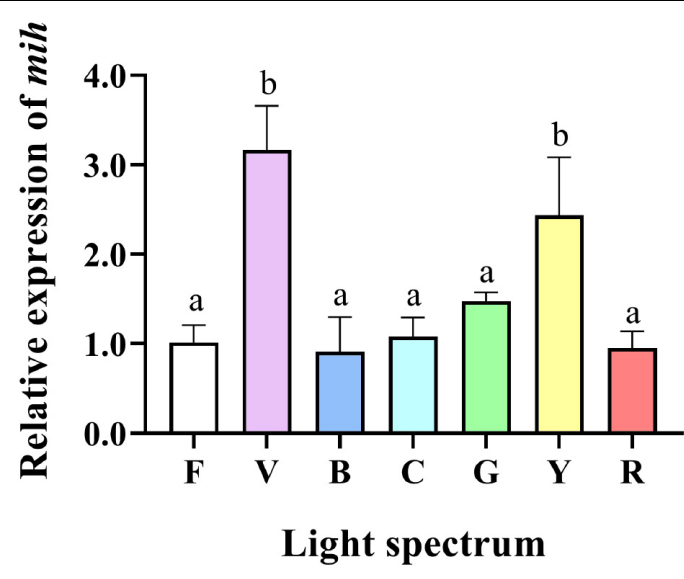

FIGURE 7 | Gene expression of molt-inhibiting hormone ( $m i h)$ gene in the eyestalk of $S$. paramamosain reared under the various light spectrum. Values are expressed as means $\pm \mathrm{SD}$ ( $n=3,2$ individuals per replicate). F, Full spectrum; V, Violet; B, Blue; C, Cyan; G, Green; Y, Yellow; R, Red. Different superscripts denote significant differences between treatments $(P<0.05)$.

the present study were in crabs reared under violet and yellow light. As a stress indicator, cortisol is correlated to mortality and growth suppression (Tataranni et al., 1996). In crustaceans, the crustaceans hyperglycemic hormone $(\mathrm{CHH})$ secreted by X-organ and sinus gland complex (XO-SG) has similar effects than cortisol and corticosterone, by regulating the conversion of glycogen into glucose (Elwood et al., 2009; Liu et al., 2019). Although $\mathrm{CHH}$ and $\mathrm{MIH}$ are different in structure, yet they appear to have similar functions in inhibiting ecdysteroid synthesis (Chung and Webster, 2003). Thus, higher cortisol levels could lead to delayed molting and subsequently reduced growth in crabs exposed to violet and yellow lights.

Heat shock proteins (HSPs) belong to a conserved class of molecular chaperones that play essential roles in growth, development, and stress response in all living organisms (Nie et al., 2017). HSPs are used as biomarkers of stress response, especially HSP70 and HSP90 which are involved in stress and immune responses (Fu et al., 2011). As a cochaperone for HSP70, HSP40 is in the regulation of ATP hydrolysis to maintain normal physiological functions and alleviate stress-related responses (Fan et al., 2003). In the present study, the relative expression of $h s p 40$ in the violet group was significantly higher. Moreover, higher expression of $h s p 70$ was detected in blue and yellow groups, and the relative expression of $h s p 90$ was upregulated in all narrow bandwidth light treatments. These results suggest that monochromatic light may lead to stress in crabs.

Melatonin, the light perception hormone, is very conserved across animals and plays an important role in the entrainment of circadian rhythmicity although the underlying pathways remain unclear (Migaud et al., 2007b; McStay et al., 2014; Saha et al., 2019; Song Y. et al., 2020). In crustaceans, melatonin injection was shown to induce ecdysteroidogenesis and stimulate

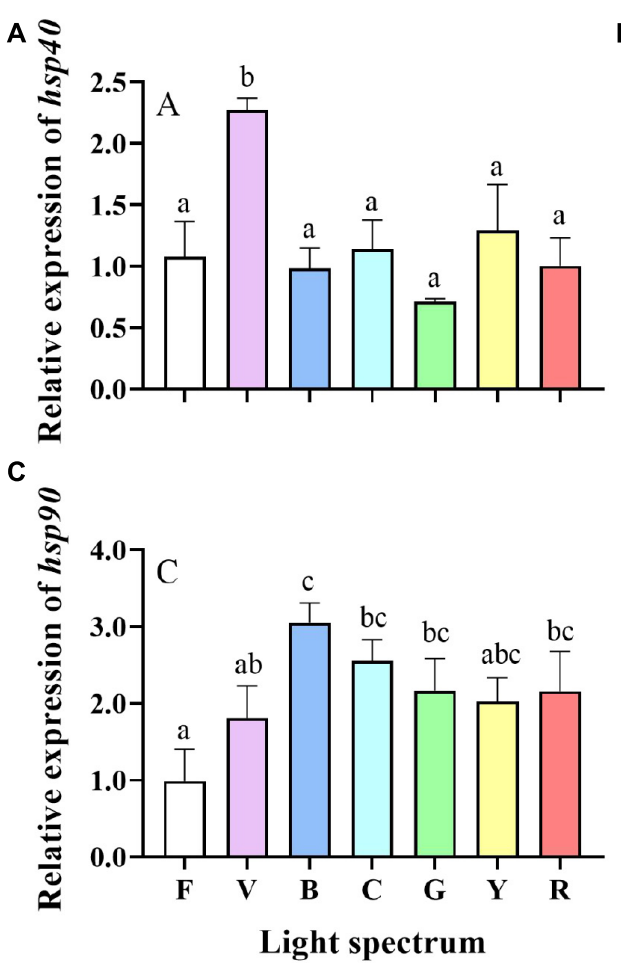

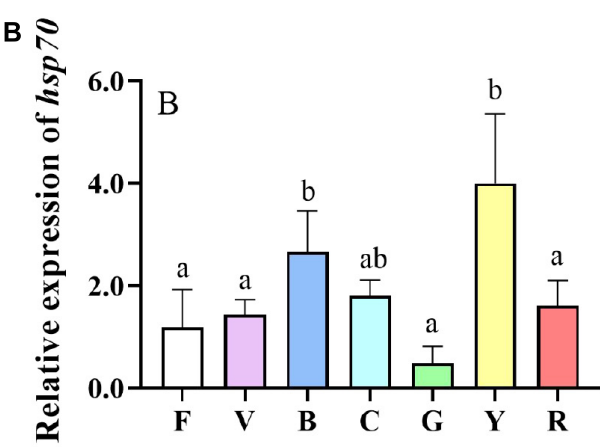

Light spectrum

FIGURE 8 | Gene expression of heat shock protein 40, 70, and 90 [hsp40 (A), hsp70 (B), and hsp90 (C)] in the hepatopancreas of S. paramamosain reared under the various light spectrum. Values are expressed as means $\pm \mathrm{SD}(n=3,2$ individuals per replicate). F, Full spectrum; V, Violet; B, Blue; C, Cyan; G, Green; Y, Yellow; $\mathrm{R}$, Red. Different superscripts denote significant differences between treatments $(P<0.05)$. 


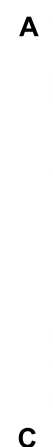

C

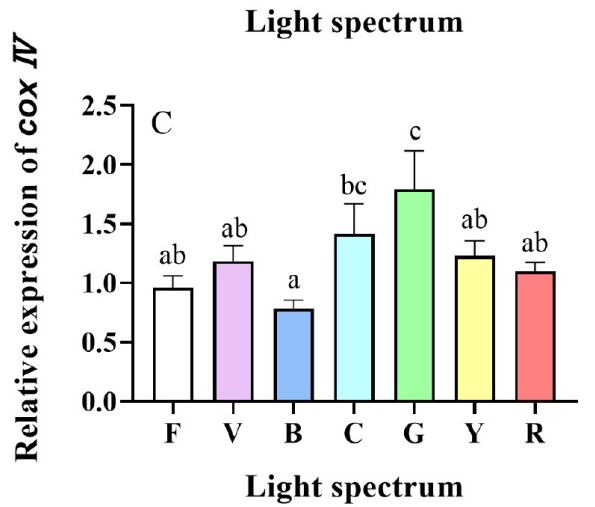

D

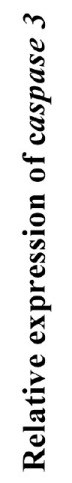

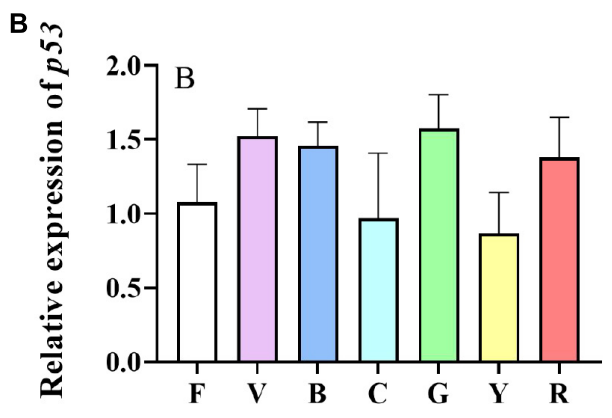

Light spectrum

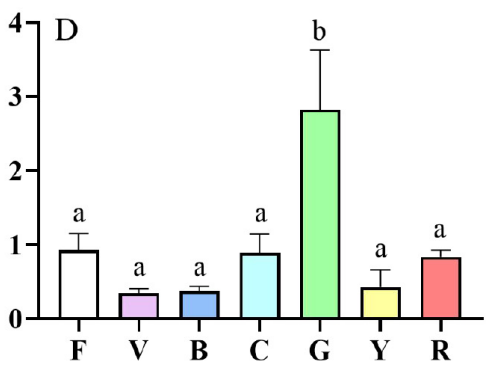

Light spectrum

FIGURE 9 | Gene expression of apoptosis-related genes [bcl-2 (A), p53 (B), cox IV (C) and caspase 3 (D)] in hepatopancreases of S. paramamosain reared under the various light spectrum. Values are expressed as means $\pm S D(n=3,2$ individuals per replicate). F, Full spectrum; V, Violet; B, Blue; C, Cyan; G, Green; Y, Yellow; $\mathrm{R}$, Red. Different superscripts denote significant differences between treatments $(P<0.05)$.

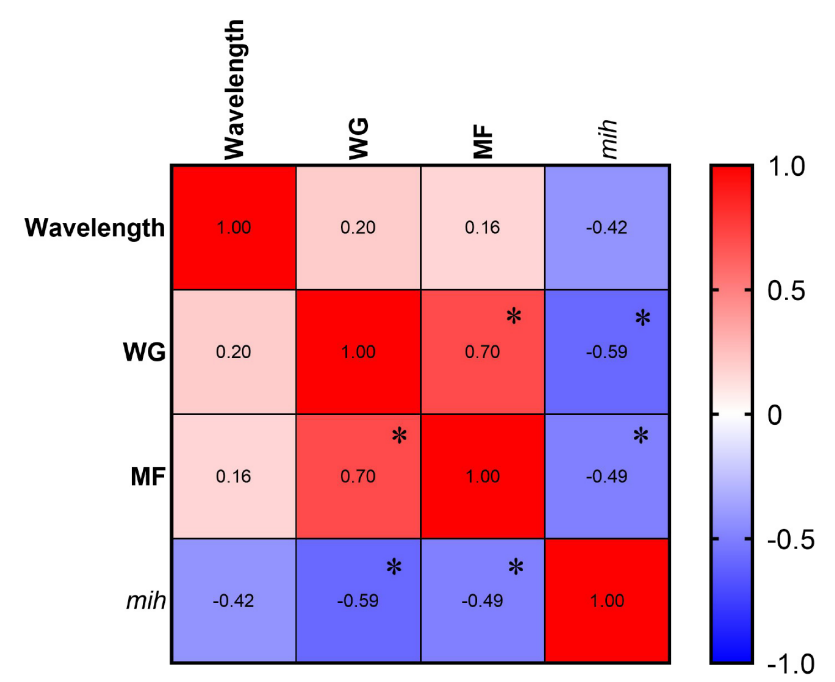

FIGURE 10 | Correlation analyses among wavelength and WG, MF, and relative expression of $\operatorname{mih}(n=3,2$ individuals per replicate of $\operatorname{mih}$, and $n=3$ replicate; and $34,31,37,37,35,32$, and 34 individuals per treatment of WG and MF. The "*" indicates $P<0.05$.

the synthesis of methyl farnesoate which is involved in the regulation of molting, leading to increased molting frequency in Scylla serrata (Sainath and Reddy, 2010b; Girish et al., 2015).
Furthermore, melatonin was shown to suppress nitric oxide synthase activity and reduce nitric oxide (Kim et al., 2004; Lee et al., 2007), which are thought to inhibit ecdysteroidogenesis mediated by MIH (Nakatsuji et al., 2009). The present study showed that short-wavelength light (blue and cyan) suppressed melatonin contents of $S$. paramamosain eyestalks. Similar results were also observed in ornamental cleaner shrimp (Lysmata amboinensis) in which melatonin content in eyestalks of shrimp reared under blue light $(455 \mathrm{~nm})$ was significantly reduced compared to red $(630 \mathrm{~nm})$ and white (control) spectral treatments (Choi et al., 2019). However, a lower melatonin level was not shown in this study to impact on molting frequency.

Antioxidant capacity refers to compounds capable of protecting cells against oxidative stress involving ROS and RNS (reactive nitrogen species) that are by-products of the metabolism and immune system. Antioxidant capacity plays an essential role in maintaining homeostasis of oxidation/reduction by antioxidant enzymes such as SOD, CAT, and glutathione peroxidase (GPX) (Karadag et al., 2009; Wu et al., 2020). Excessive accumulation of ROS may cause oxidative damage, induce disease, and lead to death in animals. MDA, the end product of lipid peroxidation by ROS, is an essential indicator that reflects oxidative damage status (Chen et al., 2021b). While no significant differences in T-AOC, SOD, and CAT were detected between light treatments, $\mathrm{H}_{2} \mathrm{O}_{2}$ and MDA were significantly higher in hepatopancreas of crabs exposed to violet light, suggesting a higher oxidative stress under this spectrum. 
Correlation analysis showed that the content of $\mathrm{H}_{2} \mathrm{O}_{2}$ was negatively correlated with wavelength. These results contrast with previously published data obtained in goldfish (Carassius auratus) and bay scallop (Argopecten irradians) that showed a reduction in $\mathrm{H}_{2} \mathrm{O}_{2}$ content under short wavelength lights (Kim et al., 2014; Song J. A. et al., 2020). Contrasting results between studies may be due to differences between species and stage of development, light characteristics of the respective habitats and tissues analyzed. Thus, further studies are required to understand the mechanisms behind such distinctions.

In the present study, $b c l-2$ gene expression in cyan, and the cox $I V$ and caspase 3 in green were upregulated. Bcl-2 is the founding member of the Bcl-2 family that can block apoptosis by preventing the release of cytochrome $c$ into the cytoplasm to suppress the activation of the caspase cascade (Chen et al., 2019). The $p 53$ is a crucial transcription factor for cell cycle arrest, cellular senescence, and apoptosis (Nuñez-Hernandez et al., 2018). Cytochrome $c$ and cytochrome c oxidase (COX) could catalyze the terminal reaction of the mitochondrial electron transport chain, reducing oxygen to water by transfers electrons to molecular oxygen (Kadenbach et al., 2004; Hüttemann et al., 2012). The results from the present study suggest that cyan light could inhibit, while green light could promote apoptosis. On the contrary, previous studies in white leg shrimp and olive flounder (Paralichthys olivaceus) showed that green light could reduce oxidative stress and apoptosis via the mitochondria-mediated caspase-dependent pathway (Kim et al., 2016; Fei et al., 2020a). Unlike $P$. vannamei and $P$. olivaceus, $S$. paramamosain is an intertidal organism that migrates between that migrates between different tidal zones. Light requirements of mud crab may therefore be more complex. Thus, the results may suggest that cyan light (a mixture of blue and green light) and full-spectrum (a mixture of all spectrum) may have some advantage over other treatments in terms of stress and apoptosis for mud crab.

\section{CONCLUSION}

In summary, this study evaluated the effects of light spectrum on the growth performance, molting, antioxidant capacity, stress response, and apoptosis-related gene expression of S. paramamosain. The results suggested that crabs under fullspectrum, cyan and blue light performed better, while violet light

\section{REFERENCES}

Bogdan, C., Röllinghoff, M., and Diefenbach, A. (2000). Reactive oxygen and reactive nitrogen intermediates in innate and specific immunity. Curr. Opin. Immunol. 12, 64-76. doi: 10.1016/s0952-7915(99)00052-7

Chen, J., Gong, Y., Zheng, H., Ma, H., Aweya, J. J., Zhang, Y., et al. (2019). SpBcl2 promotes WSSV infection by suppressing apoptotic activity of hemocytes in mud crab, Scylla paramamosain. Dev. Comp. Immunol. 100:103421. doi: 10. 1016/j.dci.2019.103421

Chen, S., Migaud, H., Shi, C., Song, C., Wang, C., Ye, Y., et al. (2021a). Light intensity impacts on growth, molting and oxidative stress of juvenile mud crab Scylla paramamosain. Aquaculture 545, 737159. doi: 10.1016/j.aquaculture. 2021.737159

Chen, S., Wu, X., Ren, Z., Mu, C., Song, W., Li, R., et al. (2021b). Effects of dietary supplementation recombined PtALF8 protein (rPtALF8) on the appeared to reduce molting and growth of $S$. paramamosain via hormonal, oxidative stress, and apoptosis pathways. Notably, the current results suggested that the optimal light wavelength for SGR is $449.97 \mathrm{~nm}$. Although more studies are required to describe and understand the underlying pathways behind light induced effects, these new results contribute to the optimization of rearing environment for mud crab farming while providing scientific hypotheses for further studies to characterize light perception and biological efficiency in crustaceans. Violet light should be avoided in the hatchery and nursery of $S$. paramamosain while blue, cyan, and full-spectrum light are recommended for juvenile on growing.

\section{DATA AVAILABILITY STATEMENT}

The raw data supporting the conclusions of this article will be made available by the authors, without undue reservation.

\section{AUTHOR CONTRIBUTIONS}

SC: methodology, data curation, visualization, and writingoriginal draft. CS: conceptualization and review and editing. HM: writing-review and editing. CbS: resources and review and editing. CM: review and editing and supervision. YY: review and editing. CW: funding acquisition. ZR: resources. All authors contributed to the article and approved the submitted version.

\section{FUNDING}

The work was supported by the National Natural Science Foundation of China (Grant Nos. 32172994 and 31972783), 2025 Technological Innovation for Ningbo (No. 2019B10010), Collaborative Promotion Program of Zhejiang Provincial Agricultural Technology of China (No. 2020XTTGSC03), Zhejiang Thousand Talents Plan awarded to HM, Ministry of Agriculture of China and China Agriculture Research System (No. CARS48), the Special research funding from the Marine Biotechnology and Marine Engineering Discipline Group in Ningbo University (No. 422004582), and K. C. Wong Magna Fund in Ningbo University.

growth performance, antioxidant capacity and gut microbial composition in swimming crab, Portunus trituberculatus. Aquaculture 537, 736456. doi: 10. 1016/j.aquaculture.2021.736456

Cheng, C.-H., Su, Y.-L., Ma, H.-L., Deng, Y.-Q., Feng, J., Chen, X.-L., et al. (2020). Effect of nitrite exposure on oxidative stress, DNA damage and apoptosis in mud crab (Scylla paramamosain). Chemosphere 239, 124668. doi: 10.1016/j. chemosphere.2019.124668

China FBOAMO (2021). China Fisheries Yearbook. Beijing: China Agriculture Press.

Choi, J. Y., Choi, Y., Kho, J., and Choi, C. Y. (2019). Effects of various photoperiods and specific wavelengths on circadian rhythm in ornamental cleaner shrimp Lysmata amboinensis. Biol. Rhythm Res. 50, 897-907. doi: 10.1080/09291016. 2018.1502237

Chung, J. S., and Webster, S. G. (2003). Moult cycle-related changes in biological activity of moult-inhibiting hormone $(\mathrm{MIH})$ and crustacean hyperglycaemic 
hormone (CHH) in the crab, Carcinus maenas. Eur. J. Biochem. 270, 3280-3288. doi: 10.1046/j.1432-1033.2003.03720.x

Cohen, J. H., and Forward, R. B. (2002). Spectral sensitivity of vertically migrating marine copepods. Biol. Bull. 203, 307-314. doi: 10.2307/1543573

Elwood, R. W., Barr, S., and Patterson, L. (2009). Pain and stress in crustaceans? Appl. Anim. Behav. Sci. 118, 128-136.

Falcón, J., Migaud, H., Muñoz-Cueto, J. A., and Carrillo, M. (2010). Current knowledge on the melatonin system in teleost fish. Gen. Comp. Endocrinol. 165, 469-482. doi: 10.1016/j.ygcen.2009.04.026

Falcón, J., Thibault, C., Begay, V., Zachmann, A., and Collin, J.-P. (1992). "Regulation of the rhythmic melatonin secretion by fish pineal photoreceptor cells," in Rhythms in Fishes, ed. M. A. Ali (Boston, MA: Springer), 167-198.

Fan, C.-Y., Lee, S., and Cyr, D. M. (2003). Mechanisms for regulation of Hsp70 function by Hsp40. Cell Stress Chaperones 8, 309-316. doi: 10.1379/14661268(2003)008\&lt;0309:mfrohf\&gt;2.0.co;2

Fei, F., Gao, X., Wang, X., Liu, Y., Bin, H., and Liu, B. (2020a). Effect of spectral composition on growth, oxidative stress responses, and apoptosis-related gene expression of the shrimp, Penaeus vannamei. Aquac. Rep. 16:100267.

Fei, F., Liu, B., Gao, X., Wang, X., Liu, Y., and Bin, H. (2020b). Effects of supplemental ultraviolet light on growth, oxidative stress responses, and apoptosis-related gene expression of the shrimp Litopenaeus vannamei. Aquaculture 520:735013.

Fu, D., Chen, J., Zhang, Y., and Yu, Z. (2011). Cloning and expression of a heat shock protein (HSP) 90 gene in the haemocytes of Crassostrea hongkongensis under osmotic stress and bacterial challenge. Fish Shellfish Immunol. 31, 118125. doi: 10.1016/j.fsi.2011.04.011

Gao, X., Li, X., Zhang, M., Shi, C., Song, C., and Liu, Y. (2015). Optimization of LED light quality and time for artificial breeding of Haliotis discus hannai. Trans. Chin. Soc. Agricult. Eng. 31, 225-231.

Gao, X., Zhang, M., Li, X., Shi, C., Song, C., and Liu, Y. (2016a). Effects of LED light quality on the growth, metabolism, and energy budgets of Haliotis discus discus. Aquaculture 453, 31-39.

Gao, X., Zhang, M., Tian, H., Zheng, J., Li, X., Song, C., et al. (2016b). Effect of LED light quality on respiratory metabolism and activities of related enzymes of Haliotis discus hannai. Aquaculture 452, 52-61.

Girish, B. P., Swetha, C. H., and Reddy, P. S. (2015). Induction of ecdysteroidogenesis, methyl farnesoate synthesis and expression of ecdysteroid receptor and retinoid $\mathrm{X}$ receptor in the hepatopancreas and ovary of the giant mud crab, Scylla serrata by melatonin. Gen. Comp. Endocrinol. 217-218, 37-42. doi: 10.1016/j.ygcen.2015.05.007

Gong, J., Yu, K., Shu, L., Ye, H., Li, S., and Zeng, C. (2015). Evaluating the effects of temperature, salinity, starvation and autotomy on molting success, molting interval and expression of ecdysone receptor in early juvenile mud crabs, Scylla paramamosain. J. Exp. Mar. Biol. Ecol. 464, 11-17.

Góth, L. (1991). A simple method for determination of serum catalase activity and revision of reference range. Clin. Chim. Acta 196, 143-151. doi: 10.1016/00098981(91)90067-m

Guo, B., Wang, F., Dong, S., and Gao, Q. (2011). The effect of rhythmic light color fluctuation on the molting and growth of Litopenaeus vannamei. Aquaculture $314,210-214$

Guo, H., Xian, J.-A., Li, B., Ye, C.-X., Wang, A.-L., Miao, Y.-T., et al. (2013). Gene expression of apoptosis-related genes, stress protein and antioxidant enzymes in hemocytes of white shrimp Litopenaeus vannamei under nitrite stress. Comp. Biochem. Phys. C 157, 366-371. doi: 10.1016/j.cbpc.2013.03. 001

Guo, Z.-X., He, J.-G., Xu, H.-D., and Weng, S.-P. (2013). Pathogenicity and complete genome sequence analysis of the mud crab dicistrovirus-1. Virus Res. 171, 8-14. doi: 10.1016/j.virusres.2012.10.002

Hüttemann, M., Helling, S., Sanderson, T. H., Sinkler, C., Samavati, L., Mahapatra, G., et al. (2012). Regulation of mitochondrial respiration and apoptosis through cell signaling: cytochrome $c$ oxidase and cytochrome $c$ in ischemia/reperfusion injury and inflammation. Biochim. Biophys. Acta 1817, 598-609. doi: 10.1016/j. bbabio.2011.07.001

Imayavaramban, L., Dhayaparan, D., and Devaraj, H. (2007). Molecular mechanism of molt-inhibiting hormone (MIH) induced suppression of ecdysteroidogenesis in the Y-organ of mud crab: Scylla serrata. FEBS Lett. 581, 5167-5172. doi: 10.1016/j.febslet.2007.09.029
Kadenbach, B., Arnold, S., Lee, I., and Hüttemann, M. (2004). The possible role of cytochrome $c$ oxidase in stress-induced apoptosis and degenerative diseases. Biochim. Biophys. Acta 1655, 400-408. doi: 10.1016/j.bbabio.2003.06.005

Kannan, K., and Jain, S. K. (2000). Oxidative stress and apoptosis. Pathophysiology 7, 153-163.

Karadag, A., Ozcelik, B., and Saner, S. (2009). Review of methods to determine antioxidant capacities. Food Anal. Methods 2, 41-60. doi: 10.1007/s12161-0089067-7

Karakatsouli, N., Papoutsoglou, E. S., Sotiropoulos, N., Mourtikas, D., StigenMartinsen, T., and Papoutsoglou, S. E. (2010). Effects of light spectrum, rearing density and light intensity on growth performance of scaled and mirror common carp Cyprinus carpio reared under recirculating system conditions. Aquac. Eng. 42, 121-127.

Kim, B.-S., Jung, S. J., Choi, Y. J., Kim, N. N., Choi, C. Y., and Kim, J.W. (2016). Effects of different light wavelengths from LEDs on oxidative stress and apoptosis in olive flounder (Paralichthys olivaceus) at high water temperatures. Fish Shellfish Immunol. 55, 460-468. doi: 10.1016/j.fsi.2016.06. 021

Kim, H.-W., Batista, L. A., Hoppes, J. L., Lee, K. J., and Mykles, D. L. (2004). A crustacean nitric oxide synthase expressed in nerve ganglia, Y-organ, gill and gonad of the tropical land crab, Gecarcinus lateralis. J. Exp. Biol. 207:2845. doi: $10.1242 /$ jeb.01117

Kim, N. N., Choi, Y. J., Shin, H. S., Lim, J. R., Han, J. M., Cho, J. H., et al. (2014). The effect of LED light spectra on antioxidant system by thermal stress in goldfish, Carassius auratus. Mol. Cell. Toxicol. 10, 47-58.

Kobayashi, S. (2012). Molting growth patterns of the Japanese Mitten Crab Eriocheir Japonica (de Haan) under laboratory-reared conditions. J. Crustacean Biol. 32, 753-761. doi: 10.1163/193724012x649796

Kohen, R., and Nyska, A. (2002). Invited review: oxidation of biological systems: oxidative stress phenomena, antioxidants, redox reactions, and methods for their quantification. Toxicol. Pathol. 30, 620-650. doi: 10.1080/ 01926230290166724

Lee, S. G., Kim, H.-W., and Mykles, D. L. (2007). Guanylyl cyclases in the tropical land crab, Gecarcinus lateralis: cloning of soluble (NO-sensitive and insensitive) and membrane receptor forms. Comp. Biochem. Phys. D 2, 332-344. doi: $10.1016 / j . c b d .2007 .08 .001$

Li, X., Li, Z., Liu, J., Zhang, T., and Zhang, C. (2011). Effects of light intensity on molting, growth, precocity, digestive enzyme activity, and chemical composition of juvenile Chinese mitten crab Eriocheir sinensis. Aquac. Int. 19, 301-311.

Liu, A., Liu, J., Chen, X., Lu, B., Zeng, C., and Ye, H. (2019). A novel crustacean hyperglycemic hormone $(\mathrm{CHH})$ from the mud crab Scylla paramamosain regulating carbohydrate metabolism. Comp. Biochem. Phys. A 231, 49-55. doi: 10.1016/j.cbpa.2019.01.015

Liu, X.-L., Xi, Q.-Y., Yang, L., Li, H.-Y., Jiang, Q.-Y., Shu, G., et al. (2011). The effect of dietary Panax ginseng polysaccharide extract on the immune responses in white shrimp, Litopenaeus vannamei. Fish Shellfish Immunol. 30, 495-500. doi: 10.1016/j.fsi.2010.11.018

Livak, K. J., and Schmittgen, T. D. (2001). Analysis of relative gene expression data using real-time quantitative PCR and the 2- $\Delta \Delta \mathrm{CT}$ method. Methods 25 , 402-408.

Luchiari, A. C., De Morais Freire, F. A., Pirhonen, J., and Koskela, J. (2009). Longer wavelengths of light improve the growth, intake and feed efficiency of individually reared juvenile pikeperch Sander lucioperca (L.). Aquac. Res. 40, 880-886. doi: 10.1111/j.1365-2109.2008.02160.x

Luo, Y. T., Sheng, C., Qian, Z. Y., and Zhang, H. Q. (2006). The ultrastructure of compound eye in the Portunus tritubereulatus under different wavelength lights adaptation. J. Mol. Biol. 39, 177-184.

McStay, E., Migaud, H., Vera, L. M., Sánchez-Vázquez, F. J., and Davie, A. (2014). Comparative study of pineal clock gene and AANAT2 expression in relation to melatonin synthesis in Atlantic salmon (Salmo salar) and European seabass (Dicentrarchus labrax). Comp. Biochem. Physiol. A Mol. Integr. Physiol. 169, 77-89. doi: 10.1016/j.cbpa.2013.12.011

Migaud, H., Davie, A., Martinez Chavez, C. C., and Al-Khamees, S. (2007a). Evidence for differential photic regulation of pineal melatonin synthesis in teleosts. J. Pineal Res. 43, 327-335. doi: 10.1111/j.1600-079X.2007.00 480. $\mathrm{x}$ 
Migaud, H., Cowan, M., Taylor, J., and Ferguson, H. W. (2007b). The effect of spectral composition and light intensity on melatonin, stress and retinal damage in post-smolt Atlantic salmon Salmo salar. Aquaculture 270, 390-404. doi: 10.1016/j.aquaculture.2007.04.064

Mukai, Y. (2011). Remarkably high survival rates under dim light conditions in sutchi catfish Pangasianodon hypophthalmus larvae. Fish. Sci. 77, 107-111. doi: 10.1007/s12562-010-0304-9

Mykles, D. L., Adams, M. E., Gäde, G., Lange, A. B., Marco, H. G., and Orchard, I. (2010). Neuropeptide action in insects and crustaceans. Physiol. Biochem. Zool. 83, 836-846. doi: 10.1086/648470

Nakatsuji, T., Lee, C.-Y., and Watson, R. D. (2009). Crustacean molt-inhibiting hormone: structure, function, and cellular mode of action. Comp. Biochem. Phys. A 152, 139-148. doi: 10.1016/j.cbpa.2008.10.012

Nasr, M. A. F., Mohammed, H., Hassan, R. A., Swelum, A. A., and Saadeldin, I. M. (2019). Does light intensity affect the behavior, welfare, performance, meat quality, amino acid profile, and egg quality of Japanese quails? Poult. Sci. 98, 3093-3102. doi: 10.3382/ps/pez089

Nie, H., Liu, L., Huo, Z., Chen, P., Ding, J., Yang, F., et al. (2017). The HSP70 gene expression responses to thermal and salinity stress in wild and cultivated Manila clam Ruditapes philippinarum. Aquaculture 470, 149-156.

Nuñez-Hernandez, D. M., Felix-Portillo, M., Peregrino-Uriarte, A. B., and YepizPlascencia, G. (2018). Cell cycle regulation and apoptosis mediated by p53 in response to hypoxia in hepatopancreas of the white shrimp Litopenaeus vannamei. Chemosphere 190, 253-259. doi: 10.1016/j.chemosphere.2017.09. 131

Ohkawa, H., Ohishi, N., and Yagi, K. (1979). Assay for lipid peroxides in animal tissues by thiobarbituric acid reaction. Anal. Biochem. 95, 351-358.

Oliveira, C., Ortega, A., López-Olmeda, J. F., Vera, L. M., and Sánchez-Vázquez, F. J. (2007). Influence of constant light and darkness, light intensity, and light spectrum on plasma melatonin rhythms in senegal sole. Chronobiol. Int. 24, 615-627. doi: 10.1080/07420520701534657

Pape, C., Teschke, M., and Meyer, B. (2008). Melatonin and its possible role in mediating seasonal metabolic changes of Antarctic krill, Euphausia superba. Comp. Biochem. Physiol. A Mol. Integr. Physiol. 149, 426-434. doi: 10.1016/j.cbpa.2008.02. 001

Peng, R., Jiang, X., Jiang, M., and Chen, S. (2019). Effect of light intensity on embryonic development of the cuttlefish Sepia lycidas. Aquac. Int. 27, 807-816.

Peskin, A. V., and Winterbourn, C. C. (2000). A microtiter plate assay for superoxide dismutase using a water-soluble tetrazolium salt (WST-1). Clin. Chim. Acta 293, 157-166. doi: 10.1016/s0009-8981(99)00246-6

Qiao, H., Jiang, F., Xiong, Y., Jiang, S., Fu, H., Li, F., et al. (2018). Characterization, expression patterns of molt-inhibiting hormone gene of Macrobrachium nipponense and its roles in molting and growth. PLoS One 13:e0198861. doi: 10.1371/journal.pone.0198861

Re, R., Pellegrini, N., Proteggente, A., Pannala, A., Yang, M., and Rice-Evans, C. (1999). Antioxidant activity applying an improved ABTS radical cation decolorization assay. Free Radic. Biol. Med. 26, 1231-1237. doi: 10.1016/s08915849(98)00315-3

Saha, S., Singh, K. M., and Gupta, B. B. P. (2019). Melatonin synthesis and clock gene regulation in the pineal organ of teleost fish compared to mammals: similarities and differences. Gen. Comp. Endocrinol. 279, 27-34. doi: 10.1016/ j.ygcen.2018.07.010

Sainath, S. B., and Reddy, P. S. (2010a). Melatonergic regulation of hemolymph sugar levels in the freshwater edible crab, Oziotelphusa senex senex. J. Exp. Zool. Part A 313A, 201-208. doi: 10.1002/jez.594

Sainath, S. B., and Reddy, P. S. (2010b). Evidence for the involvement of selected biogenic amines (serotonin and melatonin) in the regulation of molting of the edible crab, Oziotelphusa senex senex Fabricius. Aquaculture 302, 261-264.

Sainath, S. B., Swetha, C. H., and Reddy, P. S. (2013). What do we (need to) know about the melatonin in crustaceans? J. Exp. Zool. Part A 319, 365-377. doi: 10.1002/jez.1800

Shi, C., Wang, J., Peng, K., Mu, C., Ye, Y., and Wang, C. (2019). The effect of tank colour on background preference, survival and development of larval swimming crab Portunus trituberculatus. Aquaculture 504, 454-461.

Sierra-Flores, R., Davie, A., Grant, B., Carboni, S., Atack, T., and Migaud, H. (2016). Effects of light spectrum and tank background colour on Atlantic cod
(Gadus morhua) and turbot (Scophthalmus maximus) larvae performances. Aquaculture 450, 6-13.

Song, J. A., Lee, Y. S., Choi, Y.-U., and Choi, C. Y. (2020). Effects of light-emitting diodes on thermally-induced oxidative stress in the bay scallop Argopecten irradians. Molluscan Res. 40, 130-141.

Song, Y., Song, X., Wu, M., Pang, Y., Shi, A., Shi, X., et al. (2020). The protective effects of melatonin on survival, immune response, digestive enzymes activities and intestinal microbiota diversity in Chinese mitten crab (Eriocheir sinensis) exposed to glyphosate. Comp. Biochem. Phys. C 238:108845. doi: 10.1016/j.cbpc. 2020.108845

Takahashi, A., Kasagi, S., Murakami, N., Furufuji, S., Kikuchi, S., Mizusawa, K., et al. (2018). Effects of different green light intensities on the growth performance and endocrine properties of barfin flounder Verasper moseri. Gen. Comp. Endocrinol. 257, 203-210. doi: 10.1016/j.ygcen.2017.04.003

Tataranni, P. A., Larson, D. E., Snitker, S., Young, J. B., Flatt, J. P., and Ravussin, E. (1996). Effects of glucocorticoids on energy metabolism and food intake in humans. Am. J. Physiol. Endocrinol. Metab. 271, E317-E325. doi: 10.1152/ ajpendo.1996.271.2.E317

Taylor, J. F., North, B. P., Porter, M. J. R., Bromage, N. R., and Migaud, H. (2006). Photoperiod can be used to enhance growth and improve feeding efficiency in farmed rainbow trout, Oncorhynchus mykiss. Aquaculture 256, 216-234.

Ullmann, J. F. P., Gallagher, T., Hart, N. S., Barnes, A. C., Smullen, R. P., Collin, S. P., et al. (2011). Tank color increases growth, and alters color preference and spectral sensitivity, in barramundi (Lates calcarifer). Aquaculture 322-323, 235-240.

Vera, L. M., Davie, A., Taylor, J. F., and Migaud, H. (2010). Differential light intensity and spectral sensitivities of Atlantic salmon, European sea bass and Atlantic cod pineal glands ex vivo. Gen. Comp. Endocrinol. 165, 25-33. doi: 10.1016/j.ygcen.2009.05.021

Villamizar, N., García-Alcazar, A., and Sánchez-Vázquez, F. J. (2009). Effect of light spectrum and photoperiod on the growth, development and survival of European sea bass (Dicentrarchus labrax) larvae. Aquaculture 292, 80-86.

Wang, F., Dong, S., Huang, G., Wu, L., Tian, X., and Ma, S. (2003). The effect of light color on the growth of Chinese shrimp Fenneropenaeus chinensis. Aquaculture 228, 351-360.

Wang, F., Wang, X., Liu, H., and Dong, S. (2014). Effect of light color on growth and energy budget of Swimming crab (in Chinese). Period. Ocean Univ. China 44, 25-29.

Wei, J., Tian, L., Wang, Y., Yu, L., and Zhu, X. (2021). Effects of salinity, photoperiod, and light spectrum on larval survival, growth, and related enzyme activities in the giant freshwater prawn, Macrobrachium rosenbergii. Aquaculture 530:735794. doi: 10.1016/j.aquaculture.2020.735794

Wu, C., Lu, B., Wang, Y., Jin, C., Zhang, Y., and Ye, J. (2020). Effects of dietary vitamin $\mathrm{D}_{3}$ on growth performance, antioxidant capacities and innate immune responses in juvenile black carp Mylopharyngodon piceus. Fish Physiol. Biochem. 46, 2243-2256. doi: 10.1007/s10695-020-00876-8

Wu, L., Wang, Y., Li, J., Song, Z., Xu, S., Song, C., et al. (2021). Influence of light spectra on the performance of juvenile turbot (Scophthalmus maximus). Aquaculture 533, 736191. doi: 10.1016/j.aquaculture.2020.736191

Wyllie, A. H., Kerr, J. F. R., and Currie, A. R. (1980). "Cell death: the significance of apoptosis," in International Review of Cytology, eds G. H. Bourne, J. F. Danielli, and K. W. Jeon (Cambridge, MA: Academic Press), 251-306. doi: 10.1016/s0074-7696(08)62312-8

Xu, H., Wang, J., Han, T., Li, X., Zheng, P., Yin, F., et al. (2019). Effects of dietary phospholipids levels on growth performance, lipid metabolism, and antioxidant capacity of the early juvenile green mud crab, Scylla paramamosain (Estampador). Aquac. Res. 50, 513-520. doi: 10.1111/are.13 922

Yang, M., Chen, Z., Hu, F., Sun, J., Ding, J., Chang, Y., et al. (2020). Light spectra regulated foraging and feeding behaviors shed light on stock enhancement of the sea urchin Strongylocentrotus intermedius. Aquac. Rep. 18:100480. doi: 10.1016/j.aqrep.2020.100480

Yang, W., Zheng, W., Chai, M., and Fan, T. (1985). Single receptor system in the compound eye of crabs (Scylla serrata). Acta Physiol. Sin. 37, 61-69.

Yang, Z., Wei, B., Liu, Q., Cheng, Y., and Zhou, J. (2018). Individual growth pattern of juvenile stages of the Chinese mitten crab (Eriocheir sinensis) reared under laboratory conditions. Aquac. Int. 26, 645-657. 
Yuan, Q., Wang, Q., Zhang, T., Li, Z., and Liu, J. (2017). Effects of water temperature on growth, feeding and molting of juvenile Chinese mitten crab Eriocheir sinensis. Aquaculture 468, 169-174.

Zhang, C., Yang, X.-Z., Xu, M.-J., Huang, G.-Y., Zhang, Q., Cheng, Y.-X., et al. (2018). Melatonin promotes cheliped regeneration, digestive enzyme function, and immunity following autotomy in the Chinese mitten crab, Eriocheir sinensis. Front. Physiol. 9:269. doi: 10.3389/fphys.2018.00269

Zimmer-Faust, R. K. (1989). The relationship between chemoreception and foraging behavior in crustaceans. Limnol. Oceanogr. 34, 1367-1374.

Conflict of Interest: The authors declare that the research was conducted in the absence of any commercial or financial relationships that could be construed as a potential conflict of interest.
Publisher's Note: All claims expressed in this article are solely those of the authors and do not necessarily represent those of their affiliated organizations, or those of the publisher, the editors and the reviewers. Any product that may be evaluated in this article, or claim that may be made by its manufacturer, is not guaranteed or endorsed by the publisher.

Copyright (c) 2022 Chen, Shi, Migaud, Song, Mu, Ye, Wang and Ren. This is an open-access article distributed under the terms of the Creative Commons Attribution License (CC BY). The use, distribution or reproduction in other forums is permitted, provided the original author(s) and the copyright owner(s) are credited and that the original publication in this journal is cited, in accordance with accepted academic practice. No use, distribution or reproduction is permitted which does not comply with these terms. 